\title{
Cuboid Bone
}

National Cancer Institute

\section{Source}

National Cancer Institute. Cuboid Bone. NCI Thesaurus. Code C32414.

A bone on the lateral side of the tarsus between the calcaneus and the fourth and fifth metatarsal bones. 